\title{
DENDRIMER-COATED SAW ARRAYS FOR VOLATILE ORGANIC DETECTION: ARRAY SIZE AND SIGNAL DEGRADATION EFFECTS
}

\author{
Gordon C. Osbourn, Antonio J. Ricco, John W. Bartholomew, and Rubel F. Martinez \\ Sandia National Laboratories, Albuquerque, New Mexico, 87185-1423 \\ Maurie E. Garcia, Robert Peez, \\ and Richard M. Crooks \\ Dept. of Chemistry, Texas A\&M University \\ Ralph Spindler and Mark E. Kaiser \\ Dendritech, Inc. \\ Midland, Michigan, 48642
}

College Station, Texas, 77843-3255

\begin{abstract}
Dendrimer film coatings for arrays of surface acoustic wave (SAW) devices were developed for the detection and recognition of volatile organic compounds (VOCs). Pattern recognition of array responses to 18 organic analytes was carried out, and correct identification with $99.5 \%$ accuracy, over wide concentration ranges, was obtained from arrays using six different coatings.
\end{abstract}

\section{INTRODUCTION}

Chemical microsensor arrays obviate the difficulty of developing a high-selectivity material for every analyte. The application of pattern recognition to the simultaneous responses of different microsensors enables the identification and quantification of multiple analytes with a single array. Maximum materials diversity is the surest means to create an effective array for many analytes [1 ], but using a single material "family" simplifies coating development.

Dendrimeric polymers, or dendrimers (Figure 1), are attractive for such arrays because they contain chemically tailorable endogenous and exogenous binding sites, in addition to tunable permeability and other physical properties $[2,3]$. Dendrimers, prepared by repetitive branching, have three anatomical features: a central core, repetitive branch units, and terminal functional groups. Dendrimers are synthesized by adding repetitive branch units to the molecule one layer, or generation, at a time in iterative growth steps. Dendrimer size increases with generation number, leading to crowding of the surface functional groups, which causes the dendrimer to adopt a spherical or globular structure as of the fourth generation. In solution, these species recognize other molecules through both exo- and endoreception. Exoreception occurs when molecular species interact strongly with functional groups at the terminus of each dendrimer arm. Endoreception, a consequence of the dendrimer's globular molecular geometry, occurs when small species penetrate the interstices between the densely packed surface groups and are solvated in the large channels of the dendrimer's core.

In this paper, we report the successful combination of an array of dendrimer films with mass-sensitive SAW sensors to correctly identify 18 organic analytes over wide concentration ranges. We show, through a combinatorial comparison of VERI $[4,5]$ pattern recognition results, that six-sensor arrays are sufficient to give reliable recognition of these analytes.

\section{EXPERIMENTAL DETAILS}

The nine films we evaluated are described by Table 1 and Figure 1, which shows schematically the covalent attachment of

dendrimers to the SAW device surface. The region of the SAW delay line between transducers is first modified by a $150-200$ nm-thick Au film, followed by a self-assembled monolayer of mercaptoundecanoic acid (MUA) [1-3]. Chemical diversity is imparted to the dendrimers through bulk-phase coupling of appropriate terminal functional groups, elaborated in Table 1 and Figure 1, with the primary-amine-terminated dendrimer surface. Next, reaction of the dendrimers' few remaining unfunctionalized amines with the MUA monolayer yields amidelinked dendrimer films on the SAW devices.

Design and fabrication of SAW devices have been described elsewhere, as have measurement electronics and gasflow system for our SAW array measurements [4], which we currently perform on 12 chemically functionalized SAW sensors simultaneously. The $97-\mathrm{MHz}$ ST-quartz SAW delay lines, with accurate control of temperature $\left(+/-0.02{ }^{\circ} \mathrm{C}\right)$, provide short-term frequency stability of $\sim 0.3 \mathrm{~Hz}$, yielding a surface mass/area detection limit of $100 \mathrm{pg} / \mathrm{cm}^{2}$.

Table 2 shows 18 organic analytes that were examined in this work. This group of analytes contains multiple examples from several classes of VOCs, including simulants for nerve agents (the organophosphonates), as well as water. It also contains kerosene, which itself is a complex mixture of VOCs.

Table 1. Films used for SAW arrays.

\begin{tabular}{cl} 
No. & Terminal groups \\
\hline$l^{*}$ & $\mathrm{OH}(48 \%)$ and $\mathrm{NH}_{2}(52 \%)$ \\
$2 *$ & $\mathrm{NH}_{2} / \mathrm{NHR}, \mathrm{R}=\mathrm{C}-6(21 \%)^{\mathrm{a}}$ \\
3 & $\mathrm{NH}_{2} / \mathrm{NHR} / \mathrm{NR}_{2}, \mathrm{R}=\mathrm{C}-6(61 \%)^{\mathrm{a}}$ \\
4 & $\mathrm{NH}_{2} / \mathrm{NHR}, \mathrm{R}=\mathrm{C} 2-$ phenyl $(21 \%)^{\mathrm{a}}$ \\
$5 *$ & $\mathrm{NH}_{2} / \mathrm{NHR}, \mathrm{R}=\mathrm{C}-6(2.5 \%)^{\mathrm{a}}$ \\
$6 *$ & $\mathrm{CH}_{3}\left(\mathrm{CH}_{2}\right)_{15} \mathrm{SH}^{\mathrm{b}}$ \\
$7^{*}$ & $\mathrm{AEEA}(45 \%)$ and $\mathrm{NH}_{2}(55 \%)$ \\
8 & $\mathrm{NH}_{2}$ \\
$9 *$ & $\mathrm{NH}_{2} / \mathrm{NHR}, \mathrm{R}=\mathrm{C}-12(20 \%)^{\mathrm{a}}$
\end{tabular}

*These films comprise the "best-6" set, for which isotherms are depicted in Figure 2.

${ }^{a}$ Indicates percentage of $\mathrm{N}-\mathrm{H}$ bonds replaced by $\mathrm{R}$ to form NHR and $\mathrm{NR}_{2}$ terminal groups (see Figure 1).

${ }^{\mathrm{h}}$ This self-assembled alkanethiol-based monolayer is not depicted in Figure 1; all other films are dendrimers, as shown in the figure. 


\section{SENSOR RESPONSES}

The ability of an array to distinguish different analytes can be partially understood by viewing projections of the full array response, where the signal of each individual sensor is plotted along an orthogonal axis. Analytes can be distinguished if the clusters of points, associated with different concentrations of different analytes, are geometrically separate. Figure 2 shows a 2-D projection of 6-D response data for the best six-dendrimer array (films identified by "*" in Table 1); the 18 isotherms are displayed in two groups of nine for clarity. Sensor responses were preprocessed to provide equalized response ranges, and a constant-length vector was added to all responses to move the isotherms radially away from the origin.

To evaluate robustness of compound identification in the presence of signal degradation, each 6-D isotherm in Figure 2 includes mathematically calculated random film sensitivity losses of 0 to $8 \%$ in all dimensions (creating "clouds" of points at higher concentrations-the righthand regions of the isotherms). At low concentrations (lefthand regions of the isotherms), the responses range from moderately different (lower group of isotherms) to very different (upper group of isotherms): at submonolayer coverages, adsorption energy differences due to variation in film chemical functionalities are most pronounced. In contrast, the response curves are more nearly parallel for many of the 18 analytes at high concentrations (righthand regions of the isotherms), consistent with physical multilayer adsorption, a process which is dominated by analyte heat of condensation, not film/analyte interaction chemistry. Note that similar slopes does not imply that all analytes have the same heat of adsorption; rather, for each individual analyte, it implies that a change in its partial pressure evokes a comparable change in surface coverage for all the different sensor coating materials.

The data of Figure 2 illustrate that the responses from the different analytes are distinct, and the different analytes should be distinguishable using appropriate pattern-recognition techniques. However, the distributions of responses are quite complex, and are not easily converted into any of the simple forms needed for statistical-based pattern-recognition (PR) analysis.

\section{DATA ANALYSIS}

We analyzed the SAW/dendrimer array data using the VERI PR technique $[4,5]$, a newly-developed multivariate analysis method based on an empirical model of human cluster perception. VERI analysis correctly treats arbitrarily complex sensor response distributions, and automatically determines the multivariate decision thresholds necessary to produce appropriate class volume shapes for the array responses to any chemical analyte. Appropriate class volume shapes are needed to obtain correct estimates of the chemical recognition performance of sensor arrays and to achieve the most effective discrimination against unknown analytes (i.e., those not in the training set). VERI leave-one-out analysis quantitatively compares the chemical recognition performance of alternative choices of SAW films, and thus finds the optimal subset of a group of films for a set of target analytes. These results enable quantitative array-element selection comparisons not possible with principal-component analysis $[5,6]$. Inclusion of modeled sensor response degradation into the VERI leave-one- out analysis provides a comparison of the robustness of array responses for different film combinations.

Figure 3 shows a subset of results from VERI leave-oneout analysis of all possible coated-SAW array combinations of the nine films of Table 1. Shown are best and worst array performance $v s$. array size, including the effects of film sensitivity changes over the array lifetime, using an ensembleaging model $[\mathbf{5}, \mathbf{6}]$. The maximum sensitivity loss for any sensor is set at $8 \%$ or $16 \%$, as indicated in the figure. Arrays of 5 or more sensors enable good chemical discrimination $(99.5 \%$ accuracy with 6 films), with no improvement using more than six devices. Comparison of the $8 \%$ and $16 \%$ results also shows that there is no improvement in robustness against sensor response degradation by increasing the number of array sensors beyond six.

\section{CONCLUSIONS}

Dendrimer films have been shown to provide a range of chemical responses which make them useful in SAW array applications. Future work will explore the additional chemical recognition capability that results from combining selected dendrimer films with other classes of SAW coatings.

Sandia is a multiprogram laboratory operated by Sandia Corporation, a Lockheed Martin Company, for the United States Department of Energy under Contract DE-AC04-94AL85000. We gratefully acknowledge the excellent technical assistance of Alan W. Staton of Sandia Labs, and the financial support of DOE's Office of National Security and Nonproliferation, NN-20, as well as the National Science Foundation (CHE-9313441).

\section{REFERENCES}

1. A. J. Ricco, R. M. Crooks, and G. C. Osbourn, "SAW Chemical Sensor Arrays: New Chemically Sensitive Interfaces Combined with Novel Cluster Analysis to Detect Volatile Organic Compounds and Mixtures," Accts. Chem. Res., 3 1, xxxx (1998).

2. R. M. Crooks and A. J. Ricco, "New Organic Materials Suitable for Use in Chemical Sensor Arrays," Accts. Chem. Res., 31, xxxx (1998).

3. R. M. Crooks, H. Tokuhisa, A. J. Ricco, G. C. Osbourn, M. Kaiser, and R. Spindler, "Chemical Sensors Based on Surface-Confined Dendrimers," Proc. Symp. Chem. and Biol. Sensors and Anal. Electrochem. Methods, 97-19, The Electrochemical Society, Pennington (1997), pp. 134 140 .

4. A. J. Ricco, G. C. Osbourn, J. W. Bartholomew, R. M. Crooks, C. Xu, and R. E. Allred, "New Materials and Multidimensional Cluster Analysis for SAW Chemical Sensor Arrays," Technical Digest of the 1994 Solid-State Sensor and Actuator Workshop, Transducers Research Foundation, Cleveland (1994), pp. $180-183$.

5. G. C. Osboum, J. W. Bartholomew, A. M. Bouchard, and R. F. Martinez, "Automated Pattern Recognition Based on the Visual Empirical Region of Influence (VERI) Method: A User's Guide", http://www.sandia.gov/1100/1155Web/ 1155 home.htm

6. G. C. Osbourn, J. W. Bartholomew, A. J. Ricco, and G. C. Frye, "VERI Pattern Recognition Applied to Chemical Microsensor Array Selection and Chemical Analysis," Accts. Chem. Res., 31 , xxxx (1998). 
Table 2. Analytes arranged by chemical class.

\begin{tabular}{|c|c|c|}
\hline Chemical class & Compounds studied & Number/symbol \\
\hline $\begin{array}{l}\text { Aliphatic } \\
\text { hydrocarbon }\end{array}$ & $\begin{array}{c}\text { cyclohexane } \\
n \text {-hexane } \\
i \text {-octane } \\
\text { kerosene }^{\mathrm{h}}\end{array}$ & $\begin{array}{l}1+ \\
2- \\
3- \\
4-\end{array}$ \\
\hline $\begin{array}{c}\text { Aromatic } \\
\text { hydrocarbon }\end{array}$ & $\begin{array}{l}\text { benzene } \\
\text { toluene }\end{array}$ & $\begin{array}{l}5+ \\
6-\end{array}$ \\
\hline $\begin{array}{l}\text { Chlorinated } \\
\text { hydrocarbon }\end{array}$ & $\begin{array}{l}\text { carbon tetrachloride } \\
\text { trichloroethylene } \\
\text { chlorobenzene }\end{array}$ & $\begin{array}{l}7+ \\
8- \\
9+\end{array}$ \\
\hline Alcohol & $\begin{array}{c}\text { methanol } \\
n \text {-propanol } \\
\text { pinacolyl alcohol }\end{array}$ & $\begin{array}{l}10- \\
11- \\
12-\end{array}$ \\
\hline Ketone & $\begin{array}{l}\text { acetone } \\
\text { methyl isobutyl ketone }\end{array}$ & $\begin{array}{l}13+ \\
14-\end{array}$ \\
\hline $\begin{array}{l}\text { Organophosphorous } \\
\text { compound }\end{array}$ & $\begin{array}{l}\text { dimethylmethylphosphonate } \\
\text { diisopropylmethylphosphonate } \\
\text { tributylphosphate }\end{array}$ & $\begin{array}{l}15- \\
16+ \\
17-\end{array}$ \\
\hline Water & $\mathrm{H}_{2} \mathrm{O}$ & $18-$ \\
\hline
\end{tabular}

${ }^{\mathrm{a}}$ Refers to isotherms of Figure 2.

'kerosene is typically a mixture of $n$-dodecane, several alkyl derivatives of benzene, naphthalene, and a pair of tetrahydronaphthalenes.

'2, 2-dimethyl-3-butanol

\section{G4 PAMAM Dendrimer}
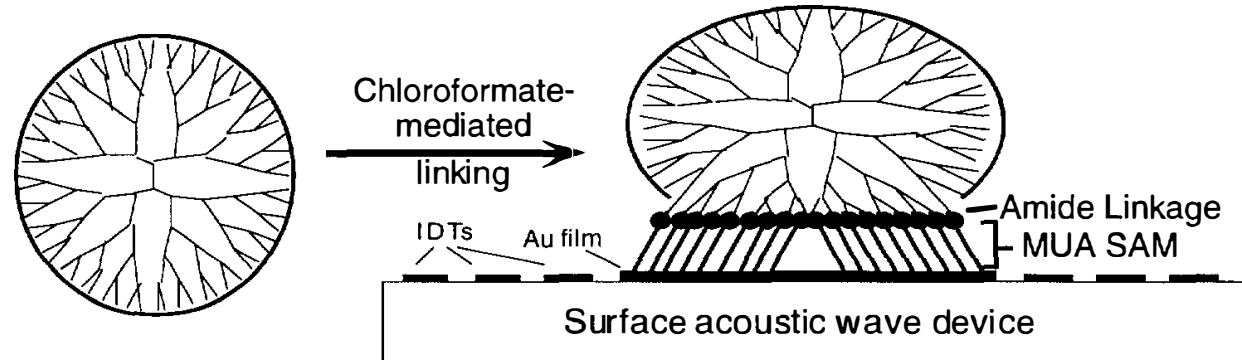

Branches $=-\mathrm{N}\left(\mathrm{CH}_{2} \mathrm{CH}_{2} \mathrm{CONHCH} \mathrm{CH}_{2} \mathrm{~N}-\right)_{2}-$

Terminal groups $=-\mathrm{NH}_{2},-\mathrm{OH},-\mathrm{AEEA}$ (below), $-\mathrm{NHR}$, or $-\mathrm{NR}_{2}$

$(\mathrm{R}=\mathrm{C}-6, \mathrm{C}-12$, or C2-Phenyl shown below)<smiles>CCCCC(O)CC</smiles>

C-6<smiles>CCC(O)c1ccccc1</smiles>

C2-Phenyl<smiles>CCC(C)CC(C)CC</smiles>

$\underline{C-12}$<smiles>CCCNCCO</smiles>

$\underline{A E E A}$

Figure 1. Depiction of $4^{\text {th }}$-generation PAMAM (polyamidoamine) dendrimer and its attachment to an $A$ u film on the SAW device surface (top). Each branch terminates either with $-\mathrm{NH}_{2},-\mathrm{OH}, \mathrm{AEEA}$, $-\mathrm{NHR}$, or $\mathrm{NR}_{2} ; R$ is given in the figure. Table 1 identifies film compositions used in SAW arrays. 


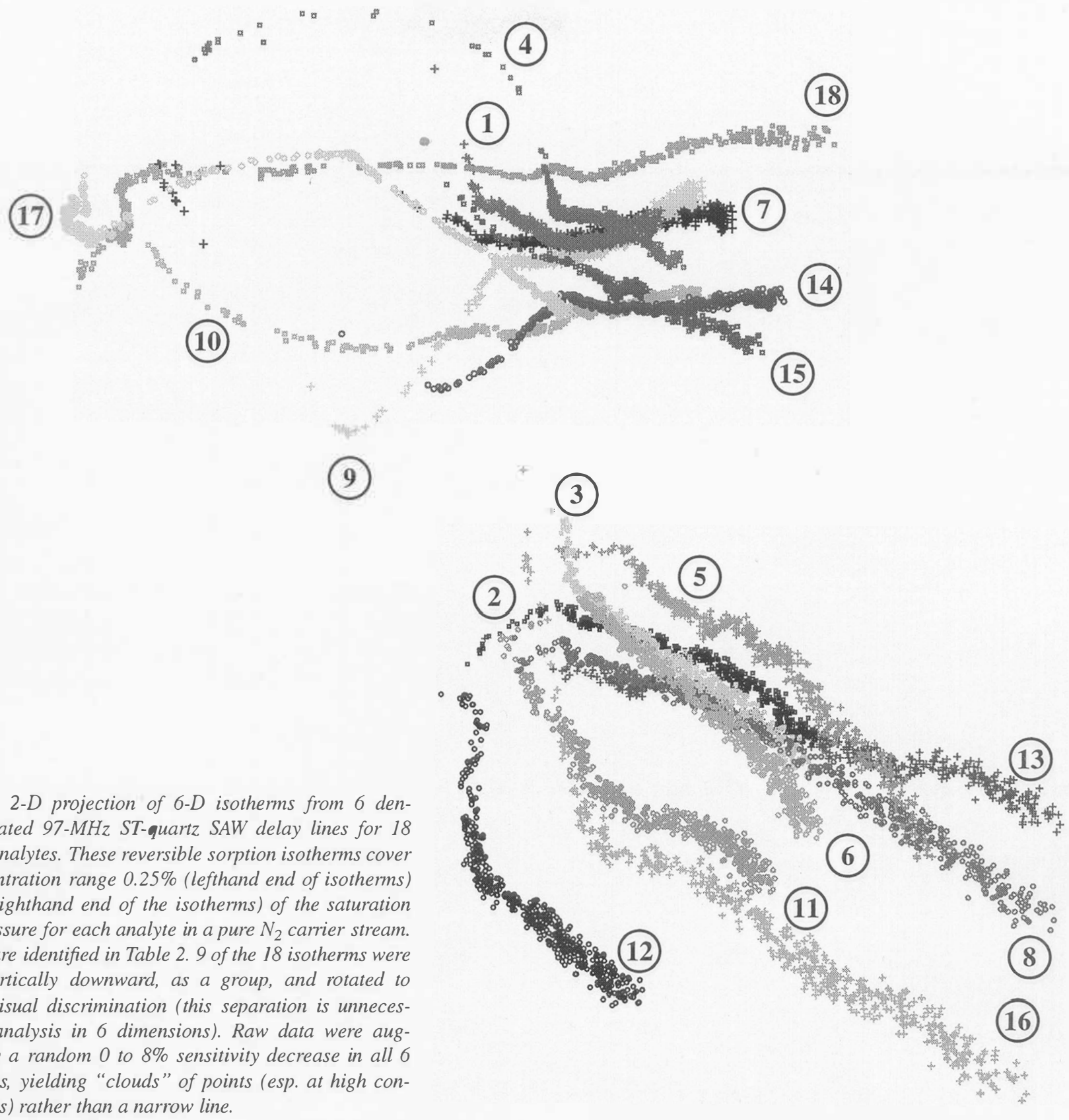

Figure 2. 2-D projection of 6-D isotherms from 6 dendrimer-coated 97-MHz ST-quartz SAW delay lines for 18 different analytes. These reversible sorption isotherms cover the concentration range $0.25 \%$ (lefthand end of isotherms) to $50 \%$ (righthand end of the isotherms) of the saturation vapor pressure for each analyte in a pure $\mathrm{N}_{2}$ carrier stream. Analytes are identified in Table 2. 9 of the 18 isotherms were shifted vertically downward, as a group, and rotated to improve visual discrimination (this separation is unnecessary for analysis in 6 dimensions). Raw data were augmented by a random 0 to $8 \%$ sensitivity decrease in all 6 dimensions, yielding "clouds" of points (esp. at high concentrations) rather than a narrow line.

Figure 3. Rate of error in identifying all concentrations of all 18 analytes (Table 2) as a function of the number of sensors selected for the array. Open circles show the situation when the best-performing array of $\mathrm{n}$ sensors $(\mathrm{n}=2-9)$ is selected from the 9 dendrimer films evaluated, in the presence of either $8 \%$ (lowest curve) or $16 \%$ (middle curve) random degradation in signal fidelity. Solid circles show the worst-performing arrays of 2 - 9 sensors in the presence of $8 \%$ signal degradation. Note that the performance difference between best and worst arrays is more than a factor of 2 for the smallest array, converging to zero when all 9 materials are used.

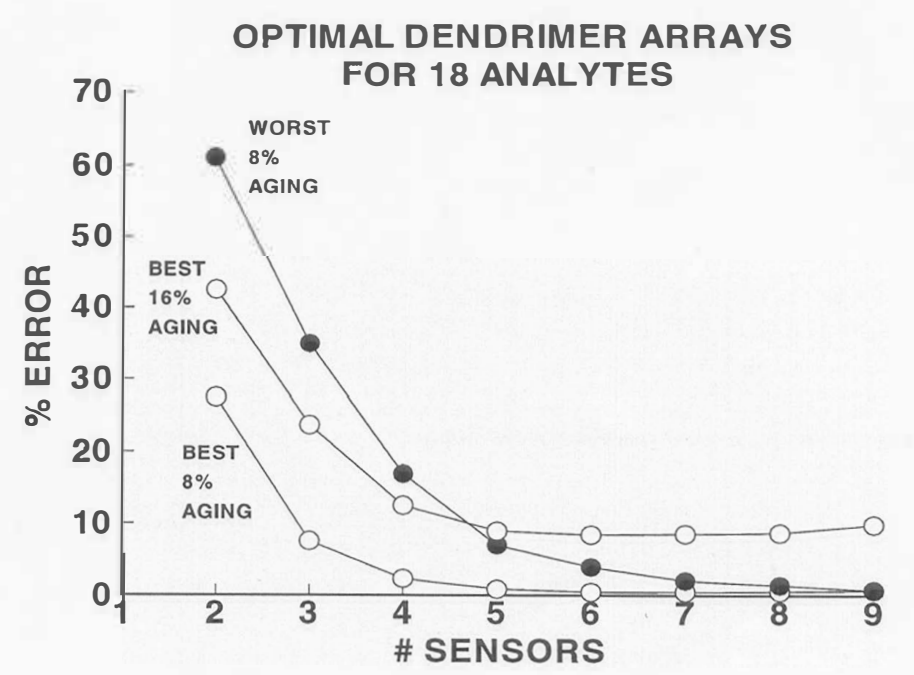

